\title{
Portfolio Selection and VaR Estimation: Evidence from Western Balkan Countries
}

\author{
Llesh Lleshaj ${ }^{*}$, Alban Korbi \\ Faculty of Economy, University of Tirana, Albania
}

Received September 16, 2020; Revised October 15, 2020; Accepted November 29, 2020

\section{Cite This Paper in the following Citation Styles}

(a): [1] Llesh Lleshaj, Alban Korbi , "Portfolio Selection and VaR Estimation: Evidence from Western Balkan Countries," Universal Journal of Accounting and Finance, Vol. 8, No. 4, pp. 92 - 102, 2020. DOI: 10.13189/ujaf.2020.080402.

(b): Llesh Lleshaj, Alban Korbi (2020). Portfolio Selection and VaR Estimation: Evidence from Western Balkan Countries. Universal Journal of Accounting and Finance, 8(4), 92 - 102. DOI: 10.13189/ujaf.2020.080402.

Copyright $\odot 2020$ by authors, all rights reserved. Authors agree that this article remains permanently open access under the terms of the Creative Commons Attribution License 4.0 International License

\begin{abstract}
The risk-return relationship is an analysis especially for the investors who are risk aversion. In this context, their decision to invest in an investment strategy is a complex process. This complexity is larger for financial capital markets which are not very liquid. Hence, the aim of this study is the analysis of stock exchange capitalization in the Western Balkans Region, and the possibility of building an efficient frontier curve of investments, and finding the optimal potential portfolio. In this study, we analyzed the daily stock quotations of the five Western Balkan countries which are not members of the European Union, and these data are proceeded by five indexes with the official daily publications of quotations. The time-series data are divided into three semi-annual (2019 and 2020). The analysis also has calculations in terms of return on the capital distribution as well as the risk level. Realizing this major purpose used Lagrange multipliers and interpolating polynomial methods, which have generated the efficient frontier curves. Whereas, determining the profit or loss intervals based on the risk point used VaR and CVaR estimation techniques according to the Monte Carlo simulation for geometric Brownian motion for the historical data of daily logarithmic returns. The major hypothesis in this study finds out that the stock exchange indexes of the Western Balkans Region are not efficient (in the equilibrium) because an optimal portfolio cannot be found according to the active investing, nevertheless exists a possibility diversification only for the passive investing.
\end{abstract}

Keywords Stock Exchange in the Western Balkans Region, VaR and CVaR, Efficient Frontier

\section{Introduction}

Investors who are risk aversion generally follow an axiom: "to invest in financial securities with the highest possible return and the lowest possible risk". The risk-return relationship is directly related, complicating investment operations and making them much more complex than an investor might think making the right investment in financial terms means making an efficient decision, but when the investor is active in the financial securities market, he must first know the efficient investment frontier and then makes the appropriate investment. On the other hand, the classic evaluation in the risk-return relationship according to the capital allocation line (CAL), does not give the full meaning of the investment and the risk that an investor faces in reality. Therefore, for risk analysis, the most suggested technique in the field of investing in financial securities is the value at risk (VaR) and the conditional value at risk (CVaR).

In this study, we analyzed the daily stock quotations of the five Western Balkan countries which are not members of the European Union (Serbia, Bosnia-Herzegovina, Montenegro, North Macedonia, and Albania). These data were selected from the official publications for three 6-monthly periods (the first semi-annual 2019; the second semi-annual 2019; and the first semi-annual 2020). The main purpose of this study is to answer some major questions: Is a diversifying investment, the portfolio that composes financial securities or capital throughout the Region? Does there exist a correlation between stock 
exchange market indexes in this Region? Which is the best position for a risk aversion investor related to risk premium and drift and volatility of daily quotations? If the indexes will perform according to historical data, what is the profit or loss interval in the future? etc. The basic hypothesis of the study is:

Null hypothesis: "the simultaneous distribution of the capital on the stock exchanges of the Western Balkans Region is potentially an efficient (equilibrium) market and could exist an optimal potential portfolio."

There are three main reasons why this study was conducted:

Firstly, there is no previous quantitative study that quantified this financial aspect for the capital market in this region and evaluates the interaction effect in the stock exchange market indexes in this region (by the same investor and at the same time). In this way, it would increase the efficiency and liquidity level of these markets.

Secondly, what is the maximum level of performance and risk by investing in this stock exchanges? How attractive would local and foreign investors be to invest their capital in these financial markets? These countries are aspiring to join the European Union, therefore how available are they to compete across European capital markets?

Thirdly, stimulating the academic and professional debate on the capital market in the Region and identifying the progress orientations, challenges, and solutions. Moreover, the aim is to operate in the max and potential level of capitalization. Especially at a time when the covid-19 pandemic is expected to bring about a global and regional economic crisis. In order to realize the purpose of this study for derived optimal portfolio from the efficient investment frontier, we used Lagrange multipliers and interpolating polynomial methods. While to determine the profit or loss intervals, maximum and expected values, at different levels of significance, were used VaR and CVaR estimation techniques according to the Monte Carlo simulation for geometric Brownian motion based on historical logarithmic returns data with the normal distribution.

\section{Literature Review}

Portfolio selection solves the problem of how to allocate the capital to a large number of securities so that the investment can bring a most profitable return and minimize the risk. Markowitz [29,30] suggests that investors should decide the allocation of their investment on the basis of a trade-off between risk and return based on mean-variance analysis. In finance and risk management field are suggested numerous innovations of the concept of meanvariance analysis and risk of portfolio [16]. In the last decades, the concept of portfolio selection with an uncertain investment horizon is elaborated in different ways, but the first research dynamic optimal portfolio selection problem had been started in 1971 by Merton. Years later [23] consider an optimal dynamic investment problem which assumes that markets are complete and the eventual exit is a completely endogenous factor - a stopping time of asset price filtration. Also, Blanchet-Scalliet, Karoui and Martellini [9] investigate the pricing problems associated with an uncertain time horizon.

Nowadays, efficient portfolio analysis enlarges further concepts in risk management and finance, which tries to analyze the capital market under imperfect information. In portfolio optimization, it is a rather common approach to represent the risk preferences of investors by utility functions. Most of the utility functions used in the literature fall within the family of hyperbolic absolute risk aversion functions [11].

Over the last two or three decades, various researchers have analyzed efficient frontier valuation and optimal portfolio as a matter of mathematical optimization techniques in conditions of uncertainty, orienting the study to estimates the biasing probability distribution of price volatility $[14,17,34]$. Thinking in this idea, the definition of risk is the probability of an adverse outcome. There are many research works that minimize the probability of an adverse outcome and the popular risk measurement is Value at Risk [12].

Value at Risk (VaR) is one of the most widely used risk measures in finance. VaR was popularized by J.P. Morgan in the 1990s. The executives at J.R Morgan wanted their risk managers to generate one statistic at the end of each day, which summarized the risk of the firm's entire portfolio. According to research by Alexander, Baptista and Yan [3] VaR model is used for portfolio risk management as part of their decision-making processes, and this model can be used for making portfolio selection decisions even when an agent's behavior is consistent with Prospect Theory. The whole market risk faced by the company, VaR has become a necessary implementation in any professional corporate risk management. $\mathrm{VaR}$ is not only applicable in exploring the market risk but also in managing all other types of risk. This entire system is primarily designed for both risk management and regulatory purposes. It is broadly used by most financial institutions, commercial banks, and investment banks to estimate the potentially maximal loss of their portfolio during a given time period for a given market condition. VaR can be defined as a set margin, which is the minimal loss under the confidence interval of a horizontal time [22]. This technique is a conditional quantile of the asset return loss distribution. This technique uses historical simulation, which has two main advantages: (i) the method is very easy to implement; (2) it does not depend on parametric assumptions on the distribution of the return portfolio. However, $\mathrm{VaR}$ has a main disadvantage related to approaching results completely dependent on the data set 
[15]. Nevertheless, each VaR method has its own level of accuracy as well as its own level of computational effort with full Monte Carlo simulation having the greatest accuracy for non-linear portfolios but also requiring the most computational effort [12].

In order for the optimal portfolio analysis not to remain in estimates of the value of the maximum "threshold" loss, recently in many studies instead of $\mathrm{VaR}$ is used Conditional Value-at-Risk (CVaR), which is a weighted average of this loss. This is a widely used method in the field of risk management. According to the research of Acerbi and Tasche [2] this method deal with the asymmetric distribution of asset return better than meanvariance analysis, especially for assets with returns that are heavy-tailed (as are market shares).

\section{Research Methodology}

In this study, the methodology is based on Lagrange Multipliers and Lagrange Interpolation. The first is used to calculate the efficient frontier of the indexes in the study, while the second is used to calculate the polynomial function of the efficient frontier. This study also analyzes the level in the point of view of risk through the CVaR method based on historical data on mathematical expectation and variability by simulating Monte Carlo according to the geometric Brownian motion method.

\subsection{Mean-variance Portfolio Optimization}

The basic investment concept for investor risk aversion is the possibility of investment in securities only when existing a positive correlation risk-return. Based on this principle Markowitz [29] developed and published the analytical technique of creating an efficient frontier of risky financial securities. This means efficiently diversified financial portfolios, which constitute an efficient investment frontier.

From the point of view of building a well-diversified portfolio with " $\mathrm{n}$ " financial securities and grouping " $\mathrm{m}$ " efficient portfolios, it is realized by the efficient investment frontier. Such a problem is solved analytically by using mathematical and statistical methods. The question is, how much should be invested in each index in the study to have a certain level of return with minimal risk? The answer is given through matrices:

$$
\mathrm{X}=\left(\begin{array}{c}
\mathrm{x}_{1} \\
\mathrm{x}_{2} \\
\vdots \\
\mathrm{x}_{n}
\end{array}\right) ; R=\left(\begin{array}{c}
r_{1} \\
r_{2} \\
\vdots \\
r_{n}
\end{array}\right) ; \mathrm{e}=\left(\begin{array}{c}
1 \\
1 \\
\vdots \\
1
\end{array}\right)
$$

and

$$
V=\left(\begin{array}{cccc}
S_{11} & S_{12} & \ldots & S_{1 n} \\
S_{21} & S_{22} & \ldots & S_{2 n} \\
\ldots & \ldots & \ldots & \ldots \\
S_{n 1} & S_{n 2} & \ldots & s_{n n}
\end{array}\right)
$$

Where: " $\mathrm{X}$ " is the vector of weighted capital invested in the capital market (in this study we have 5 indexes i.e. $n=1$, $2, \ldots, 5)$. "R" is the vector of return capital market index (in this study we have an average daily return divided by semi-annual, in 2019 and 2020). "E" is the unit vector that has n elements. "V" is the variance-covariance matrix of the index return indexes in the study. " $\mathrm{s}_{\mathrm{ij}}$ " is the covariance of the "i-th" index with the "j-th" index. Our problem in finding efficient portfolios for each of the $r^{*}$ fixed return:

$$
\left\{\begin{array}{c}
\mathrm{e}^{\mathrm{T}} X=1 \\
R^{\mathrm{T}} X=r^{*}
\end{array} \Rightarrow r i s k \min \sigma^{2}=f(\min )=\mathrm{X}^{\mathrm{T}} \mathrm{VX}\right.
$$

$\mathrm{e}^{\mathrm{T}}, \mathrm{R}^{\mathrm{T}}$, and $\mathrm{X}^{\mathrm{T}}$ are denoted the transposed matrices, respectively for $e, R$, and $X$. In financial literature, the risk is the minimum variance of the portfolio $\sigma^{2}$. Such a problem is solved with the Lagrange multipliers for finding conditional extremums [26]. This technique transforms the initial problem into a parametric function:

$$
\left\{\begin{array}{l}
\sum_{\mathrm{i}=1}^{n} \mathrm{x}_{\mathrm{i}}-1=0 \\
\sum_{\mathrm{i}=1}^{n} \mathrm{x}_{\mathrm{i}} r_{\mathrm{i}}-r^{*}=0
\end{array} ; \text { for minimization of } \mathrm{V}(\mathrm{x})=\sum_{\mathrm{i}=1}^{n} \sum_{\mathrm{j}=1}^{n} \mathrm{x}_{\mathrm{i}} \mathrm{x}_{\mathrm{j}} s_{\mathrm{ij}}\right.
$$

and the Lagrange function is:

$$
\mathrm{F}(\min )=\sum_{\mathrm{i}=1}^{n} \sum_{\mathrm{j}=1}^{n} \mathrm{x}_{\mathrm{i}} \mathrm{X}_{\mathrm{j}} \mathrm{S}_{\mathrm{ij}}+\lambda_{1}\left[\sum_{\mathrm{i}=1}^{n} \mathrm{x}_{\mathrm{i}} r_{\mathrm{i}}-r^{*}\right]+\lambda_{2}\left[\sum_{\mathrm{i}=1}^{n} \mathrm{x}_{\mathrm{i}}-1\right]
$$

Finding the minimum or efficient values is given by partial derivatives equal to zero:

$$
\left\{\begin{array}{l}
\partial F / \partial \mathrm{x}_{1}=2 \mathrm{x}_{1} s_{11}+2 \mathrm{x}_{2} s_{12}+\ldots+2 \mathrm{x}_{n} s_{1 n}+\lambda_{1} r_{1}+\lambda_{2}=0 \\
\partial F / \partial \mathrm{x}_{2}=2 \mathrm{x}_{1} s_{21}+2 \mathrm{x}_{2} s_{22}+\ldots+2 \mathrm{x}_{n} s_{2 n}+\lambda_{1} r_{2}+\lambda_{2}=0 \\
\ldots \\
\partial F / \partial \mathrm{x}_{n}=2 \mathrm{x}_{1} s_{n 1}+2 \mathrm{x}_{2} s_{n 2}+\ldots+2 \mathrm{x}_{n} 2 s_{n n}+\lambda_{1} r_{n}+\lambda_{2}=0 \\
\partial F / \partial \lambda_{1}=r_{1} \mathrm{x}_{1}+r_{2} \mathrm{x}_{2}+\ldots+r_{n} \mathrm{x}_{n}-r^{*}=0 \\
\partial F / \partial \lambda_{2}=\mathrm{x}_{1}+\mathrm{x}_{2}+\ldots+\mathrm{x}_{n}-1=0
\end{array}\right.
$$

Solving this quadratic programming using Microsoft Office Excel Solver \& VBA, we will get for each index the weighted capital investment in the efficient portfolio. The fixed return portfolio $r^{*}$ movies in the interval $\left(r_{\min } ; r_{\max }\right)$. These extreme return values of the interval corresponding to the possibility of securities portfolios.

\subsection{Polynomial Interpolation of Efficient Portfolio}

After the discrete evaluations of some efficient portfolios, with the purpose of evaluating the function of the efficient frontier, it used the polynomial interpolation 
technique according to the Lagrange interpolation method.

Definition. Interpolation will be called the function of non-nodes, $f(x)$, which is defined at $n+1$ node points $\left(x_{0}\right.$, $\left.f_{0}\right),\left(x_{1}, f_{1}\right), \ldots,\left(x_{n}, f_{n}\right)$ where the node points $x_{i}$ are in the segment $[a, b]$ such as $a=x_{0}<x_{1}<\ldots<x_{n}=b$ and $f_{i}=$ $f\left(x_{i}\right)$.

Let $P_{n}(x)=a_{0}+a_{1} x+a_{2} x^{2}+\ldots+a_{n} x^{n}$ be a polynomial of degree $n$. If $P_{n}(x)$ is interpolated from node points $x_{0}, x_{1}$, $x_{2}, \ldots, x_{n}$, according to the definition of interpolation we have:

$$
\left(\begin{array}{rrrrr}
1 & x_{0} & x_{0}^{2} & \ldots & x_{0}^{n} \\
1 & x_{1} & x_{1}^{2} & \ldots & x_{1}^{n} \\
& & \vdots & & \\
1 & x_{n} & x_{n}^{2} & \ldots & x_{n}^{n}
\end{array}\right)\left(\begin{array}{c}
a_{0} \\
a_{1} \\
\vdots \\
a_{n}
\end{array}\right)=\left(\begin{array}{c}
f_{0} \\
f_{1} \\
\vdots \\
f_{n}
\end{array}\right)
$$

This mean, if $n+1$ are given and defined node points $x_{0}$, $x_{1}, x_{2}, \ldots, x_{n}$ and their function values $f_{0}, f_{1}, f_{2}, \ldots, f_{n}$ of a function $f(x)$ to the points $f\left(x_{i}\right)=f_{i}$, for $i=0,1,2, \ldots, n$ then exists a single polynomial $P_{n}(x)$ with polynomial degrees at most " $n$ ", such as $P_{n}\left(x_{i}\right)=f_{i}$ for any $i=0,1,2, \ldots, n$ and the coefficients of this polynomial are the matrix system roots with dimensions $(n+1) \times(n+1)$.

The basic Lagrange interpolation function is a function based on the interpolation of an $n$-degree polynomial defined at $n+1$ node points. It will be denoted by the general form interpolated function $g\left(x_{i}\right)=f_{i}$ and will be $g(x)$ such as:

$$
g(x)=\sum_{i=0}^{n} f_{i} L_{i}(x)
$$

Where and $L_{i}(x)$ is a polynomial of degree $n$, which accotding to each node points $i$ :

$$
\mathrm{L}_{\mathrm{i}}\left(\mathrm{x}_{\mathrm{j}}\right)= \begin{cases}0 & i \neq j \\ 1 & i=j\end{cases}
$$

In fact $L_{i}(x)$ is the basic Lagrange function in the interpolation method and the general form of function is $L_{i}\left(x_{j}\right)$ :

$$
\mathrm{L}_{\mathrm{i}}\left(\mathrm{x}_{\mathrm{j}}\right)=\prod_{i \neq j} \frac{\left(x-x_{j}\right)}{\left(x_{i}-x_{j}\right)} ; i, j=0,1,2, \ldots, n
$$

\subsection{VaR and CVaR Approach}

The analysis included in this study is based on Monte Carlo simulations of Brownian motion and construction of the VaR (value at risk) estimation for the return indexes. According to the Brownian motion simulation, the quote (in this study is converted in return) $S$ is a random walk with the characteristics:

(1) For each $0=t_{0}<t_{1}<\ldots<t_{n}$, the martingals of time quote: $\mathrm{S}_{\mathrm{t} 1}-\mathrm{S}_{\mathrm{t}}, \mathrm{S}_{\mathrm{t} 2}-\mathrm{S}_{\mathrm{t} 1}, \ldots, \mathrm{S}_{\mathrm{t}-1}-\mathrm{S}_{\mathrm{tn}}$ are independent.

(2) Mathematical expectation $E\left[S_{t, i}-S_{t, i+1}\right]=0$ and variance $\mathrm{V}\left[\mathrm{S}_{\mathrm{t}, \mathrm{i}}-\mathrm{S}_{\mathrm{t}, \mathrm{i}+1}\right]=\mathrm{t}_{\mathrm{i}+1}-\mathrm{t}_{\mathrm{i}}$.
VaR model measures the value of the lowest expected loss in conditions of normal distribution market trend, for the specified interval of time and specific confidence level. How much can you lose with a probability? The answer to this question is given by $\mathrm{VaR}$ (the lowest quartile of potential losses that might occur in a portfolio during a specific time [8]. VaR has a very substantial meaning in portfolios estimates when analyzing quantitative data with normal distribution. Based on the central limit theorem (and the law of large numbers) our data complete this feature because semi-annual days/observations are taken in the analysis. Following [34], is denoted $\mathrm{f}(\mathrm{x}, \mathrm{y})$ the loss of a portfolio with decision vector $x \in X \subseteq R^{n}$ and random vector $y \in R^{n}$ that represents the value of underlying risk factors at maturity of the investment horizon $T$. Suppose that $E(|f(x, y)|)<+\infty$ for each $x \in X$ and $y \in R^{n}$ has a continuous density function $\mathrm{p}(\mathrm{y})$, then the probability cumulative distribution of the loss not exceeding a threshold $\alpha$, is given by:

$$
\Phi(x, \alpha)=\int_{f(x, y) \leq \alpha} p(y) d y
$$

When is given a confidence level $\beta$, the VaR model of portfolio $x$ is:

$$
\operatorname{VaR}_{\beta}(x)=\min \{\alpha \in R: \Phi(x, \alpha) \geq \beta\}
$$

Definition. The portfolio with value function $\mathrm{F}(\mathrm{x}, \mathrm{y})$ and with cumulative distribution $\Phi(\mathrm{x}, \alpha)$, has its $\mathrm{VaR}$ at a confidence $\beta$ in the opposite sign of the value $(1-\beta)$ quantile:

$$
\operatorname{VaR}_{\beta}=-\Phi(x, \alpha)^{(-1)}(1-\beta)
$$

where $\Phi(\mathrm{x}, \alpha)^{(-1)}$ is the quasi-inverse of the cumulative distribution function. The corresponding $\mathrm{CVaR}$ is defined as the conditional expectation of the loss of the portfolio exceeding or equal to VaR [19]:

$$
C \operatorname{VaR}_{\beta}(x)=\frac{1}{1-\beta} \int_{f(x, y) \geq \operatorname{VaR}_{\beta}(x)} f(x, y) p(y) d y
$$

The remaining task in optimizing a portfolio using the $\mathrm{CVaR}$ approach is to achieve the precise knowledge of the distribution of random vector $y$ with a given explicit investment horizon. More specifically, the investor should know the density function $p(y)$ of the random vector $y$ at maturity of the investment horizon. The difference $\beta$-VaR is the smallest value such as the probability that the loss is more than or equal to this value must be Prob. $\geq \beta$ [33]. If we call $\mathrm{CVaR}+$ (upper $\mathrm{CVaR}$ ) the expected value of losses exactly exceeds VaR (Expected Shortfall), then CVaR is a weighted average of $\mathrm{VaR}$ and $\mathrm{CVaR}+$.

An asset with the initial time of investment zero, the asset price at exit time $t, S_{t}$, has the return from time 0 to time $t$ :

$$
y=\frac{S_{t}-S_{0}}{S_{0}}
$$


The first type of uncertainty is the asset price risk, which is due to the irregular fluctuation of the asset price for a given realization of $t$, for example, geometric Brownian motion [1,31].

A general introduction to asset pricing $\mathrm{VaR}$ is adapted from Linsmeier and Pearson [25] and Jorion [21]. According to this study, the lognormal distribution is a more reasonable distribution for many asset prices (which cannot become negative) than the normal distribution. Suppose that the return $[$ return $=\ln ($ price relative $)]$ on the portfolio is normally distributed with annual mean $\mu$ and annual standard deviation $\sigma$ and the current value of the portfolio is $S_{0}$. The logarithm of the portfolio value at time $t$, $S_{t}$, is normally distributed:

$$
S_{t}=S_{0} e^{\left(\mu-\frac{\sigma^{2}}{2}\right) t} \Rightarrow \ln \left(\frac{S_{t}}{S_{t-1}}\right) \sim \mathrm{N}\left[\left(\mu-\frac{\sigma^{2}}{2}\right) ; \sigma \sqrt{t}\right]
$$

Lemma. VaR is subadditive if returns are Gaussian (VaR can be against portfolio diversification).

Proof: Under normality, the $\mathrm{VaR}$ depends on the volatility of the log-return. If the portfolio is made of two assets $\mathrm{X}$ and $\mathrm{Y}$, we have:

$$
\sigma^{2}(X+Y)=\sigma^{2}(X)+\sigma^{2}(Y)+2 \rho \sigma(X) \sigma(Y)
$$

Where $\rho$ is the correlation coefficient between the two risky asset. Assuming, without loss of generality, zero expected return, the $\mathrm{VaR}$ of the individual positions and the portfolio is:

$$
\begin{aligned}
\operatorname{VaR}^{X} & =-z_{1-\alpha} \sqrt{\sigma^{2}(X)} ; \operatorname{VaR}^{Y}=-z_{1-\alpha} \sqrt{\sigma^{2}(Y)} \\
\operatorname{VaR}^{X+Y} & =-z_{1-\alpha} \sqrt{\sigma^{2}(X)+\sigma^{2}(Y)+2 \rho \sigma(X) \sigma(Y)}
\end{aligned}
$$

Subadditivity holds if

$$
\operatorname{VaR}^{X+Y} \leq \operatorname{VaR}^{X}+\operatorname{VaR}^{Y}
$$

i.e.

$$
\begin{aligned}
& \sqrt{\sigma^{2}(X)+\sigma^{2}(Y)+2 \rho \sigma(X) \sigma(Y)} \leq \\
& \sqrt{\sigma^{2}(X)}+\sqrt{\sigma^{2}(Y)}=\sigma(X)+\sigma(Y)
\end{aligned}
$$

or,

$$
\begin{aligned}
& \sigma^{2}(X)+\sigma^{2}(Y)+2 \rho \sigma(X) \sigma(Y) \leq \\
& \sigma^{2}(X)+\sigma^{2}(Y)+2 \sigma(X) \sigma(Y)
\end{aligned}
$$

and this is true if and only if the correlation coefficient $\rho$ between the two risky asset is $\leq 1$, that is always the case.

In portfolio management the $V a R$ calculations are interested in losses of portfolio values over a short time period (typically several days or weeks). The formula VaR above is used over any horizon of time period. " $t$ " in formula is measured in annual terms and the daily $V a R$ corresponds to $t=1 / 252$. In these study analysis, the observations are measured in daily terms, so and $t=1$.

\section{Findings and Discussions}

\subsection{Efficient Frontier and Interpolating Its Function}

This study analyzes the data of five indexes with the official daily publications of quotations (converted to daily return rate) as in table 1 . The time-series data are divided into three semi-annual (2019 and 2020) in order to be comfortable for analyzing the difference from a semi-annual to others (both the previous semi-annual and the previous year semi-annual).

Table 1. Stock markets and countries

\begin{tabular}{|c|c|c|}
\hline Acronym & Description and State & Data source \\
\hline BELEX15 & Serbia: Belgrade Stock Exchange Index 15 & https:/www.belex.rs/eng/ \\
\hline MBI10 & $\begin{array}{c}\text { North Macedonia: Macedonia Stock Exchange } \\
\text { Index 10 }\end{array}$ \\
\hline MNSE10 & Montenegro: Montenegro Stock Exchange \\
Index 10 & http://www.montenegroberza.com/ \\
\hline SASX-10 & Bosnia and Herzegovina: Sarajevo Stock \\
Exchange Index 10 & http://www.sase.ba/v1/en-us/ \\
\hline INDEXAL & Albania: Raiffeisen Invest Index* & https://www.raiffeisen-invest.al/sq \\
\hline
\end{tabular}

Note: “*” this index is created by authors because of does not exist a stock market in Albania. INDEXAL involves three investment funds (arithmetic mean of daily return) such as Raiffeisen Prestige, Raiffeisen Invest Euro, and Raiffeisen Vizion. 
Based on these data, the Lagrange multipliers technique has been applied to calculate the weighted investment capital in the indexes of these five countries of the Western Balkans Region, which are not the European Unit member, and efficient portfolios have been found with the data of the semi-annual 2019 and 2020 following table 2 and Table 3.

According to the historical data of the indexes taken in the study, the average value of the lowest daily return is $0.01 \%$ and the highest $0.17 \%$. Therefore, by increasing the return value of the portfolio composed with all indexes together (not in terms of a short sale) with increasing the return $r *$ by $+0.01 \%$, the results figure out in the table 3 . We highlight that in both semi-annual 2019 we have a direct risk-return correlation with the minimum value at the beginning of the efficient portfolio value interval and with the largest value at the end of the efficient portfolio value interval. In the same way as the results of table 2 we have calculated the results of table 3 as follows.

The table 3 shows an unusual state of the risk-return correlation of the efficient frontier portfolios (we found out inverse correlation). The average value of the lowest daily return is $-0.16 \%$ and the highest $-0.02 \%$. Therefore by increasing the return value of the portfolio composed of all indexes together (not in terms of a short sale) with increasing return $r *$ by $+0.01 \%$, the results figure out in the table 4 . A reason which is justified by many economics experts of the countries surveyed is the impact of the covid-19 pandemic situation, that the historical data of the indexes in the study have negative values of the average returns of the first semi-annual period of 2020. Explaining the level of diversification and the risk-return relationship for efficient portfolios on an efficient investment frontier will be shown in figure 1 .

Table 2. Semi-annual 2019, investment efficient frontier

\begin{tabular}{|c|c|c|c|c|c|c|c|c|c|}
\hline \multirow{3}{*}{$\begin{array}{c}\text { Return } \\
\text { portfolio }\end{array}$} & \multicolumn{4}{|c|}{ First semi-annual 2019} & \multicolumn{5}{|c|}{ Second semi-annual 2019} \\
\hline & \multicolumn{3}{|c|}{ Weighted investment capital } & \multirow{2}{*}{$\begin{array}{c}\text { Risk } \\
\text { portfolio }\end{array}$} & \multicolumn{4}{|c|}{ Weighted investment capital } & \multirow{2}{*}{$\begin{array}{c}\text { Risk } \\
\text { portfolio }\end{array}$} \\
\hline & Index AL. & SASX-10 & BELEX15 & & Index AL. & SASX-10 & MBI10 & BELEX15 & \\
\hline $0.01 \%$ & $31.71 \%$ & $1.04 \%$ & $67.25 \%$ & $0.02 \%$ & $75.14 \%$ & $0.91 \%$ & $2.46 \%$ & $21.48 \%$ & $0.02 \%$ \\
\hline $0.02 \%$ & $78.86 \%$ & $2.55 \%$ & $18.58 \%$ & $0.05 \%$ & $89.67 \%$ & $2.75 \%$ & $7.58 \%$ & $0.00 \%$ & $0.06 \%$ \\
\hline $0.03 \%$ & $93.00 \%$ & $7.00 \%$ & $0.00 \%$ & $0.09 \%$ & $82.42 \%$ & $4.66 \%$ & $12.92 \%$ & $0.00 \%$ & $0.11 \%$ \\
\hline$\vdots$ & $\vdots$ & $\vdots$ & $\vdots$ & $\vdots$ & $\vdots$ & $\vdots$ & $\vdots$ & $\vdots$ & $\vdots$ \\
\hline $0.16 \%$ & $11.59 \%$ & $88.41 \%$ & $0.00 \%$ & $0.92 \%$ & $0.00 \%$ & $13.25 \%$ & $86.75 \%$ & $0.00 \%$ & $0.68 \%$ \\
\hline $0.17 \%$ & $5.33 \%$ & $94.67 \%$ & $0.00 \%$ & $0.98 \%$ & $0.00 \%$ & $5.77 \%$ & $94.23 \%$ & $0.00 \%$ & $0.74 \%$ \\
\hline
\end{tabular}

Source: Authors' calculations in Excel-VBA. Note: some index missing in the table due to the weight investment capital is equal to zero.

Table 3. First semi-annual 2020, investment efficient frontier

\begin{tabular}{|c|c|c|c|c|c|}
\hline \multicolumn{3}{|c|}{ Weighted investment capital } & \multicolumn{2}{c|}{ Portfolio evaluation } \\
\hline Index AL. & SASX-10 & MNSE10 & BELEX15 & Return & Risk \\
\hline $100.00 \%$ & $0.00 \%$ & $0.00 \%$ & $0.00 \%$ & $-0.02 \%$ & $0.09 \%$ \\
\hline $87.22 \%$ & $1.89 \%$ & $1.09 \%$ & $9.80 \%$ & $-0.03 \%$ & $0.18 \%$ \\
\hline $77.76 \%$ & $3.13 \%$ & $3.08 \%$ & $16.03 \%$ & $-0.04 \%$ & $0.26 \%$ \\
\hline$\vdots$ & $\vdots$ & $\vdots$ & $\vdots$ & $\vdots$ & $\vdots$ \\
\hline $0.00 \%$ & $0.00 \%$ & $7.18 \%$ & $92.82 \%$ & $-0.15 \%$ & $1.22 \%$ \\
\hline $0.00 \%$ & $0.00 \%$ & $0.00 \%$ & $100.00 \%$ & $-0.16 \%$ & $1.29 \%$ \\
\hline
\end{tabular}

Source: Authors' calculations in Excel-VBA. Note: some index missing in the table due to the weighted investment capital is equal zero. 


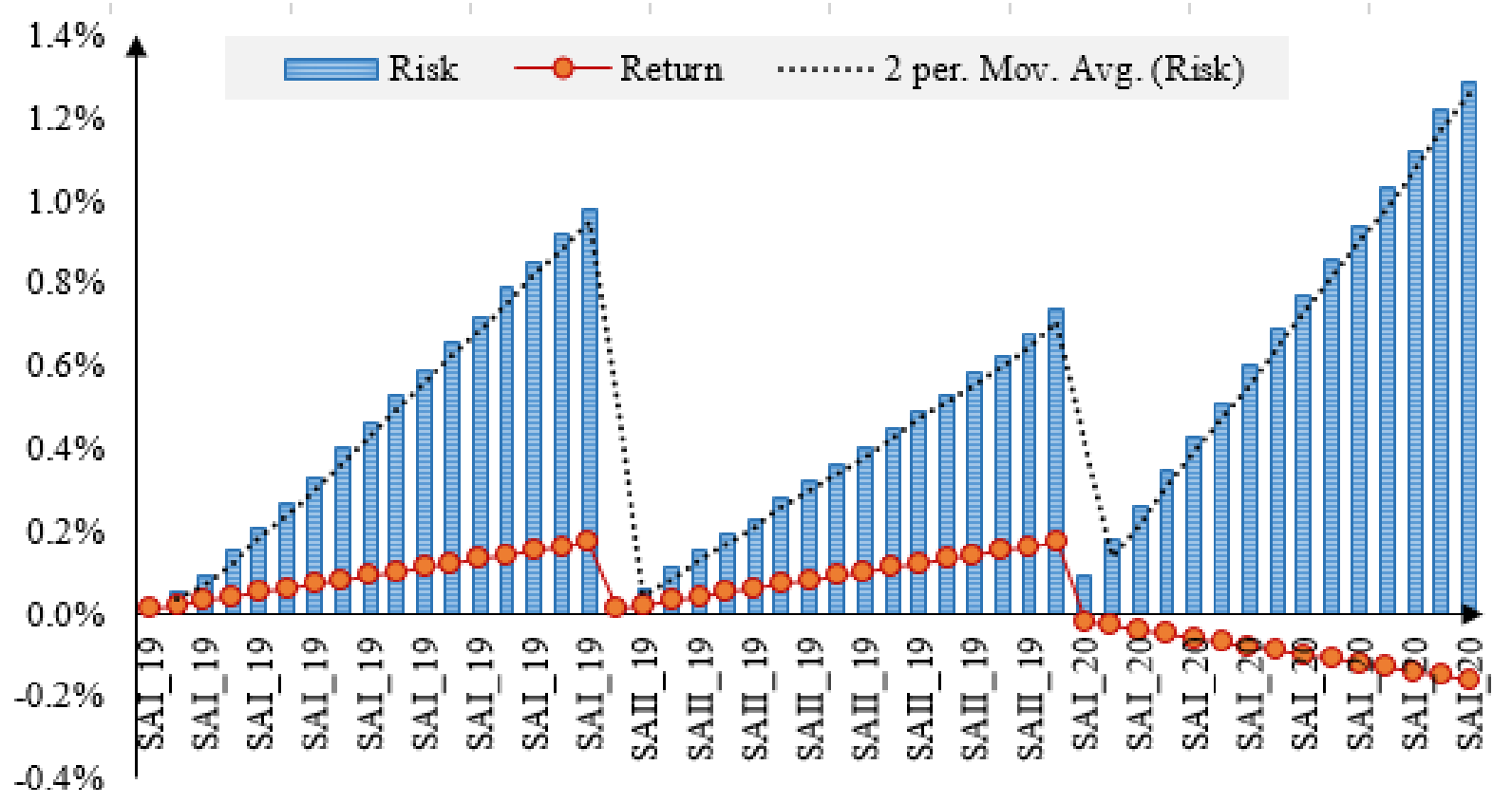

Source: Authors' calculations in Excel. Note: SAI_19 = first semi-annual 2019;

SAII_19 = second semi-annual 2019; and SAI_20 = first semi-annual 2020.

Figure 1. Efficient frontier by semi-annual

As can be seen from figure 1, the second semi-annual of 2019 is with the best risk-return correlation, so the daily risk premium of efficient portfolios in this semi-annual period is higher. The first semi-annual of 2020 is not only risky but also problematic as it has an inverse risk-return correlation. The graph moving of the investment frontier between every semi-annual is significantly changeable with no stability of quotations, this instability is present in all countries of the Western Balkans Region. When all the analyzed countries have the free-risk return higher than the value of the max return of efficient portfolios, this shows the lack of financial investment efficiency in the stock exchange markets in these countries. The phenomenon provides a low level of market performance and all rational investors (risk aversion) would not prefer to invest in these shares indexed in the stock exchanges understudy due to these countries issue treasury securities (risk-free) with a higher return than the average value of these indexes. This is also the main reason that this paper does not analyze the Capital Allocation Line (CAL) because its slope will be negative or this line does not exist. Since the CAL line cannot be constructed which is tangent to the efficient portfolio frontier, therefore an optimal portfolio (according to active investing) cannot be derived by the formula. Understanding better this, we will interpolate the performance of the efficient frontier according to the semi-annual period based on the method of Lagrange polynomial interpolation method. The simplest form of the interpolation function, which completes the efficient frontier properties (and with a very low level of error almost zero) is: $\mathrm{f}(\mathrm{x})=\mathrm{a}_{0}+\mathrm{a}_{1} \mathrm{x}+\mathrm{a}_{2} \mathrm{x}^{2}$, as in table 4 .
Table 4. Lagrange interpolating polynomial method of the efficient frontier functions

\begin{tabular}{|c|c|c|c|c|}
\hline & $f_{1}(x)$ & $f_{2}(x)$ & $f_{3}(x)$ & \\
\hline$a_{0}$ & $(-2.07630$ & -3.19610 & 1.10830 & 1 \\
\hline$a_{1}$ & 0.18060 & 0.25340 & -0.13170 & $x$ \\
\hline$a_{2}$ & 0.00010 & 0.00003 & -0.00005 & $x^{2}$ \\
\hline$R^{2}$ & 0.9987 & 0.9996 & 0.9998 & \\
\hline
\end{tabular}

Source: Authors' calculations in Excel-VBA. Note: R2 is the coefficient of determination and $\mathrm{f} 1(\mathrm{x})$ is semi-annual-I,2019; $\mathrm{f} 2(\mathrm{x})$ is semi-annual-II, 2019; and f3(x) is semi-annual-I, 2020.

These polynomial functions of the efficient frontier by semi-annual period are illustrated in figure 2 :

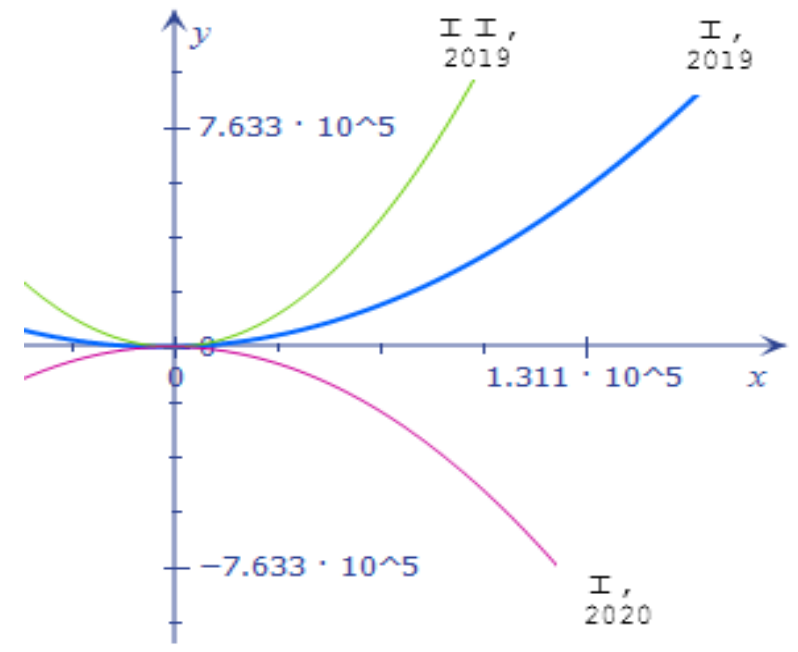

Source: Authors' calculations in Microsoft Mathematics

Figure 2. Lagrange interpolating polynomial functions of the efficient frontier 
Table 5. Correlation matrix in semi-annual for each index

\begin{tabular}{|c|c|c|c|c|c|}
\hline $\begin{array}{c}\text { SA-I, 2020 } \\
\text { SA-II, 2019 } \\
\text { SA-I, 2019 }\end{array}$ & BELEX15 & $\begin{array}{c}\text { Index } \\
\text { AL }\end{array}$ & MBI10 & MNSE10 & SASX10 \\
\hline & 1.00 & & & & \\
BELEX15 & 1.00 & & & & \\
& 1.00 & & & & \\
\hline & $\mathbf{0 . 4 8 *}$ & 1.00 & & & \\
INDEX AL & $\mathbf{- 0 . 0 3}$ & 1.00 & & & \\
& $\mathbf{0 . 3 1 *}$ & 1.00 & & & \\
\hline & $\mathbf{0 . 3 2 *}$ & $\mathbf{0 . 2 5} *$ & 1.00 & & \\
MBI10 & $\mathbf{- 0 . 1 9}$ & $\mathbf{0 . 1 5}$ & 1.00 & & \\
& --- & --- & --- & & \\
\hline & $\mathbf{0 . 3 8 *}$ & $\mathbf{0 . 4 7 *}$ & $\mathbf{0 . 1 9 * *}$ & 1.00 & \\
MNSE10 & $\mathbf{- 0 . 0 2}$ & $\mathbf{- 0 . 0 1}$ & $\mathbf{- 0 . 1 4}$ & 1.00 & \\
& $\mathbf{0 . 1 8}$ & $\mathbf{0 . 0 3}$ & --- & 1.00 & \\
\hline & -0.05 & 0.08 & 0.06 & -0.07 & 1.00 \\
SASX10 & -0.13 & 0.03 & -0.15 & 0.06 & 1.00 \\
& 0.05 & 0.00 & --- & 0.01 & 1.00 \\
\hline
\end{tabular}

Note: The statistical significance “*” $\mathrm{p}<1 \%$ and “**” $\mathrm{p}<5 \%$, and SA-I $=$ first semi-annual, SA-II = second semi-annual.

In terms of efficient markets and with the possibility of stock market capitalization, efficient frontiers should be functions which in the first quadrant of the XoY graph have the convex shape. This does not exist in non-EU Western Balkan countries, therefore this capital market is not in a position for the analysis of the construction of investment portfolios for individuals or portfolio companies who are only interested in returns resulting from the diversification of financial portfolio (long-term or short-term investment operations). On the other hand, although stock quotations may have performed poorly recently, the lack of an optimal portfolio indicates that the analyzed index functions better individually than composed in an investment portfolio, therefore these markets have no interrelationships between them. This is explained by the table 5 , which shows the correlation coefficient between the daily returns of the indexes (on a semi-annual basis). Based on the correlation analysis we note that the indexes INDEX AL, MBI10 and MNSE10 have statistically significant correlations with significance level $\mathrm{p}<1 \%$ or $\mathrm{p}<5 \%$. But this relationship is moderately negative in the first semi-annual in 2020 and nearly zero in 2019. Therefore building an optimal portfolio for the purpose of diversification by investing at the same time in several indexes of these countries is inefficient in the term risk-return optimization method.

\subsection{Var and CVaR Estimation Results}

In general VaR and CVaR analysis are assessed for investment portfolios, in our study i.e. optimal portfolio. Such a portfolio according to active investing is not defined (issue above), the analysis will be conducted looking at the level of risk according to individual indexes for each country and the optimal portfolio will be built according to the passive strategy. The results of the daily returns and risk analysis as well as, for $\mathrm{VaR}$ and $\mathrm{CVaR}$ in three levels of significance are presented in the table 6 .

Table 6. VaR and CVaR results by individual index

\begin{tabular}{|c|c|c|c|c|c|c|c|}
\hline & & & Index AL. & SASX-10 & MNSE10 & MBI10 & BELEX15 \\
\hline \multirow{8}{*}{$\begin{array}{l}\text { Semi-annual-I, } \\
2019\end{array}$} & \multicolumn{2}{|c|}{ Mean } & $0.0188 \%$ & $0.1786 \%$ & $-0.0252 \%$ & $*$ & $0.0032 \%$ \\
\hline & \multicolumn{2}{|c|}{ Volatility } & $0.0562 \%$ & $1.0422 \%$ & $0.6953 \%$ & $*$ & $0.0020 \%$ \\
\hline & \multirow{3}{*}{$\mathrm{VaR}$} & $\alpha=90 \%$ & $0.0533 \%$ & $1.1570 \%$ & $0.9163 \%$ & $*$ & $-0.0007 \%$ \\
\hline & & $\alpha=95 \%$ & $0.0737 \%$ & $1.5356 \%$ & $1.1689 \%$ & $*$ & $0.0001 \%$ \\
\hline & & $\alpha=99 \%$ & $0.1051 \%$ & $2.5130 \%$ & $2.1567 \%$ & $*$ & $-0.0048 \%$ \\
\hline & \multirow{3}{*}{ CVaR } & $\alpha=90 \%$ & $0.0799 \%$ & $1.6504 \%$ & $1.2454 \%$ & $*$ & $0.0003 \%$ \\
\hline & & $\alpha=95 \%$ & $0.0972 \%$ & $1.9711 \%$ & $1.4594 \%$ & $*$ & $0.0009 \%$ \\
\hline & & $\alpha=99 \%$ & $0.1311 \%$ & $2.5991 \%$ & $1.8783 \%$ & $*$ & $0.0021 \%$ \\
\hline \multirow{8}{*}{$\begin{array}{l}\text { Semi-annual-II, } \\
2019\end{array}$} & \multicolumn{2}{|c|}{ Mean } & $0.0060 \%$ & $0.0440 \%$ & $-0.0396 \%$ & $0.1778 \%$ & $0.0032 \%$ \\
\hline & \multicolumn{2}{|c|}{ Volatility } & $0.0163 \%$ & $0.8030 \%$ & $0.5724 \%$ & $0.7924 \%$ & $0.0019 \%$ \\
\hline & \multirow{3}{*}{ VaR } & $\alpha=90 \%$ & $0.0149 \%$ & $0.9851 \%$ & $0.7731 \%$ & $0.8377 \%$ & $-0.0008 \%$ \\
\hline & & $\alpha=95 \%$ & $0.0208 \%$ & $1.2768 \%$ & $0.9810 \%$ & $1.1256 \%$ & $-0.0001 \%$ \\
\hline & & $\alpha=99 \%$ & $0.0319 \%$ & $1.8241 \%$ & $1.3711 \%$ & $1.6656 \%$ & $0.0012 \%$ \\
\hline & \multirow{3}{*}{ CVaR } & $\alpha=90 \%$ & $0.0226 \%$ & $1.3653 \%$ & $1.0441 \%$ & $1.2128 \%$ & $0.0001 \%$ \\
\hline & & $\alpha=95 \%$ & $0.0276 \%$ & $1.6124 \%$ & $1.2202 \%$ & $1.4567 \%$ & $0.0007 \%$ \\
\hline & & $\alpha=99 \%$ & $0.0375 \%$ & $2.0962 \%$ & $1.5650 \%$ & $1.9341 \%$ & $0.0018 \%$ \\
\hline \multirow{8}{*}{$\begin{array}{l}\text { Semi-annual-I, } \\
2020\end{array}$} & \multicolumn{2}{|c|}{ Mean } & $-0.0156 \%$ & $-0.0212 \%$ & $-0.0698 \%$ & $-0.0790 \%$ & $-0.1562 \%$ \\
\hline & \multicolumn{2}{|c|}{ Volatility } & $0.0880 \%$ & $1.0691 \%$ & $0.9736 \%$ & $2.3319 \%$ & $1.2935 \%$ \\
\hline & \multirow{3}{*}{$\mathrm{VaR}$} & $\alpha=90 \%$ & $0.1283 \%$ & $1.3913 \%$ & $1.3175 \%$ & $3.0675 \%$ & $1.8139 \%$ \\
\hline & & $\alpha=95 \%$ & $0.1603 \%$ & $1.7797 \%$ & $1.6712 \%$ & $3.9147 \%$ & $2.2838 \%$ \\
\hline & & $\alpha=99 \%$ & $0.2202 \%$ & $2.5083 \%$ & $2.3347 \%$ & $5.5039 \%$ & $3.1653 \%$ \\
\hline & \multirow{3}{*}{ CVaR } & $\alpha=90 \%$ & $0.1700 \%$ & $1.8975 \%$ & $1.7785 \%$ & $4.1715 \%$ & $2.4263 \%$ \\
\hline & & $\alpha=95 \%$ & $0.1971 \%$ & $2.2265 \%$ & $2.0781 \%$ & $4.8891 \%$ & $2.8243 \%$ \\
\hline & & $\alpha=99 \%$ & $0.2500 \%$ & $2.8706 \%$ & $2.6647 \%$ & $6.2941 \%$ & $3.6037 \%$ \\
\hline
\end{tabular}

Source: Authors' calculations in Excel-VBA. Note: “*” are missing values (no publication values); mean = daily return rate and volatility = daily risk. 
If we are going to analyze an investor based on a passive investing strategy, the optimal portfolio, in this case, is approximately measurable. According to this strategy, the investor will demand performance as the market return (i.e. as the market average return), and if we analyze the average of the five indexes together for every semi-annual like a performance of the optimal portfolio, through the Lagrange multiplier method we will find the weighted investment capital in each index and the optimal portfolio risk, table 7.

The table 7 shows the passive investing strategy and the maximum loss of return which is equal to the corresponding VaR values (with significance 90\%, 95\%, and 99\%). We see the riskiest semi-annual was in 2020 for all levels of statistical confidence. If the investor loses more than the expected value VaR, this loss will be on the average equal to $\mathrm{CVaR}$, according to calculations for the first semi-annual 2020, the difference between VaR with CVaR fluctuates in the intervale $(0.21 \% ; 0.30 \%)$, indicating for a low level of loss volatility, which figures out a situation with minimal losses of the optimal portfolio according to weighted investment capital, shown in the table 7. The same result is observed for the two semi-annuals in 2019 but with a lower risk level. For more risk description of the optimal portfolio in the first semi-annual 2020, is illustrated the figure 3.

Table 7. Optimal portfolio according to passive investment strategy (passive investing) and VaR, CVaR estimators

\begin{tabular}{|c|c|c|c|c|}
\hline \multicolumn{2}{|c|}{} & Semi-annual-I, 2020 & Semi-annual-II, 2019 & Semi-annual-I, 2019 \\
\hline \multirow{2}{*}{ Mean (return) } & & $-0.0684 \%$ & $0.0383 \%$ & $0.0439 \%$ \\
\hline \multirow{3}{*}{ Volatility (risk) } & Index AL & $0.6343 \%$ & $0.1411 \%$ & $0.1689 \%$ \\
\cline { 2 - 5 } Weighted investment capital & SASX-10 & $24.0179 \%$ & $76.3361 \%$ & $84.3841 \%$ \\
\cline { 2 - 5 } & MNSE10 & $14.7576 \%$ & $6.2664 \%$ & $15.6160 \%$ \\
\cline { 2 - 5 } & MBI10 & $13.1958 \%$ & $0.0000 \%$ & $0.0000 \%$ \\
\cline { 2 - 5 } & BELEX15 & $24.9654 \%$ & $17.3974 \%$ & $*$ \\
\hline \multirow{3}{*}{ VaR } & $\alpha=90 \%$ & $0.8813 \%$ & $0.0000 \%$ & $0.0000 \%$ \\
\cline { 2 - 5 } & $\alpha=95 \%$ & $1.1117 \%$ & $0.1425 \%$ & $0.1726 \%$ \\
\cline { 2 - 5 } & $\alpha=99 \%$ & $1.5440 \%$ & $0.1938 \%$ & $0.3491 \%$ \\
\hline \multirow{3}{*}{ CVaR } & $\alpha=90 \%$ & $1.18158 \%$ & $0.2899 \%$ & $0.25258 \%$ \\
\cline { 2 - 5 } & $\alpha=95 \%$ & $1.37677 \%$ & $0.25273 \%$ & $0.30456 \%$ \\
\cline { 2 - 5 } & $\alpha=99 \%$ & $1.75895 \%$ & $0.33774 \%$ & $0.40633 \%$ \\
\hline
\end{tabular}

Source: Authors' calculations in Excel-Solver \& VBA. Note: “*” are missing values (no publication values) and “ $\alpha$ ” is the confidence level.

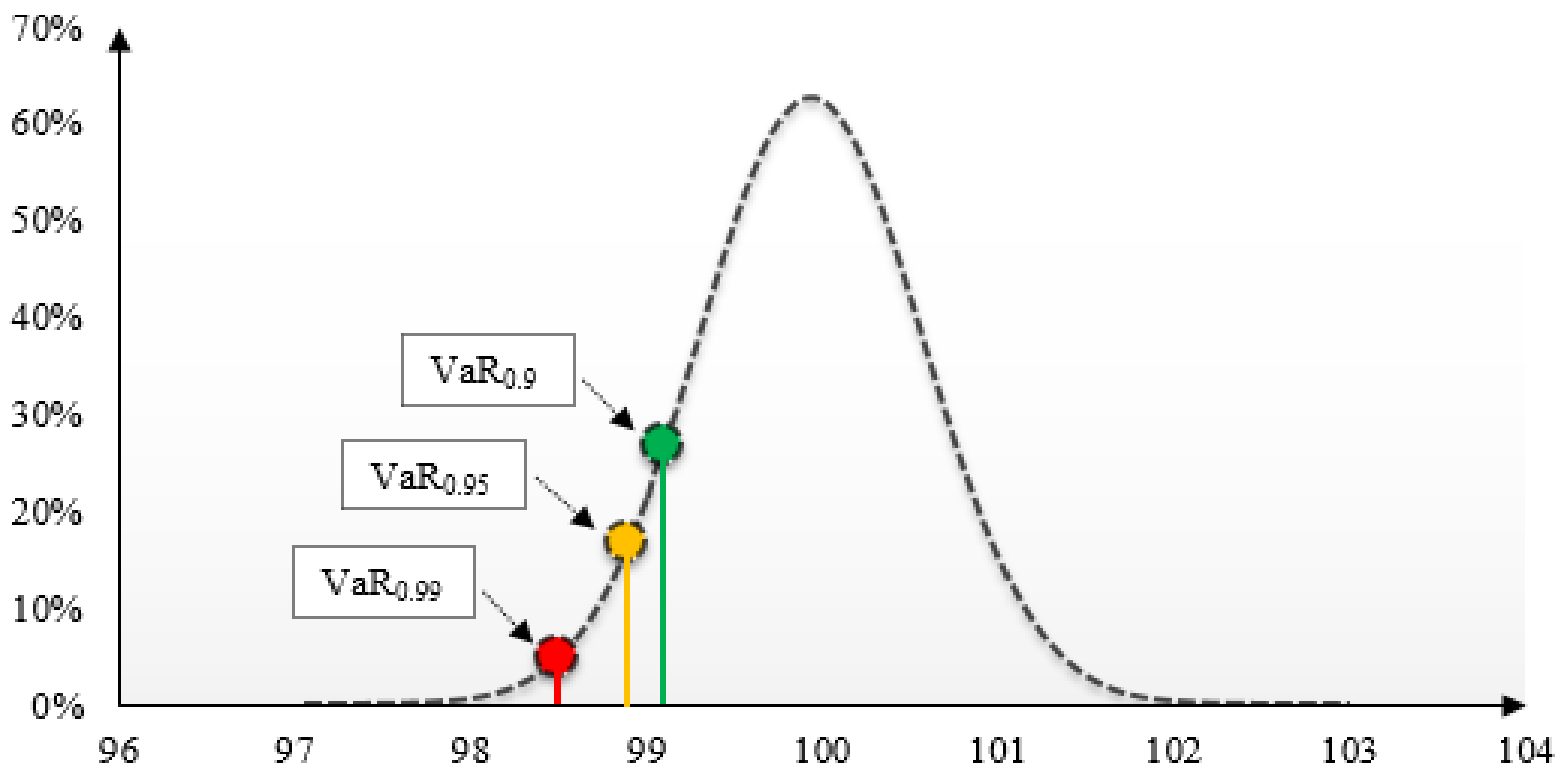

Source: Authors' calculations in Excel-Solver \& VBA.

Figure 3. VaR of optimal portfolio (passive investing) in the first semi-annual 2020 
This graphic representation is made assuming that the investor has \$100 and decides to invest in the five stock exchange indexes of the countries taken in the analysis. Simulating the geometric Brownian motion according to the normal distribution with mean $=$ return portfolio and standard deviation $=$ risk portfolio (volatility). The parameters mean and standard deviation are equivalent of return and risk of the optimal portfolio, respectively. Therefore, the graph shows three significant levels of $\mathrm{VaR}$, where the interval with \pm 3 standard deviations is from $\$ 98$ to $\$ 102$, so the maximum profit or loss is $\pm 2 \%$ (the risk level is very small if it decided to invest in these capital markets). This conclusion points out that the stock exchange indexes of the Western Balkans Region have little transactions (in value and number), and performing poorly and inefficiently, respecting the risk-return principle (currently have a very low return and risk). It is worth mentioning that the optimal portfolio according to the passive investing, has the dominant weight of investment in favor of Index in Albania (for 2019), but with a significant decrease in 2020 (in the first semi-annual in 2020 the marginal return of the index-Albania has decreased more in percentage points than the other countries).

\section{Conclusions}

This study analyzed the stock exchange market indexes for five Western Balkan countries which are not members of the European Union. The analysis is valid for short-run financial decisions and helps all domestic and foreign investors in the Region, who want to invest their capital in these stock exchange markets. Using risk and return techniques with the mathematical approach, probability and risk management, proceeding historical data of daily logarithmic returns according to the three 6-month periods in 2019 and 2020, we have found out the following conclusions:

1. In 2019, the daily return level for the efficient portfolios belongs to the interval $(0.01 \%$; $0.17 \%)$, while in 2020 it belongs to the interval $(-0.02 \%$; $-0.16 \%)$. In addition to in 2019, exist the direct risk-return correlation, while in 2020 exists the inverse correlation.

2. Even though the daily quotations on the time horizon taken into the analysis are changeable (with high volatility) for all countries, the second semi-annual of 2019 had the highest daily risk premium level as a good financial investment option.

3. The active portfolio diversification (active investing strategy) by simultaneously investing in all stock exchange market indexes, is an added risk position for investors, due to the optimal portfolio can not be estimated by the capital allocation line. This phenomenon evidently shows a lack of financial efficiency in these indexes (composed together in a portfolio).
The passive portfolio diversification (passive investing strategy) is a possible and good financial investment option. According to the value at risk, the risk position decreases significantly, and the daily return is limited (3 standard deviations is not more than $2 \%$ ). The passive investment strategy related to the largest criterion of weighted investment capital is in favor of the Albanian index.

\section{REFERENCES}

[1] Abad, P., Benito, S., and López, C., “A comprehensive review of Value at Risk methodologies", The Spanish Review of Financial Economics, 12, pp. 15-32, 2014

[2] Acerbi, C., Tasche, D., "On the coherence of expected shortfall”, Journal of Banking and Finance, 26, pp. 14871503, 2002

[3] Alexander, G., Baptista, A., and Yan, Sh., "Reducing Estimation Risk in Optimal Portfolio Selection When Short Sales are Allowed", Managerial and Decision Economics, 30, pp. 281-305, 2009.

[4] Alexander, G.J., Baptista, A.M., "Economic implication of using a mean-VaR model for portfolio selection: a comparison with mean-variance analysis", Journal of Economic Dynamics and Control, 26, pp. 1159-1193, 2002.

[5] Andersen, T., Bollerslev, T., Diebold, F., Ebens, H., “The distribution of realized stock return volatility”, Journal of Financial Economics, 61, pp. 43-76, 2001.

[6] Ballestero, E., Gunther, M., Pla-Santamaria, D., and Stummer, C., "Portfolio selection under strict uncertainty: A multi-criteria methodology and its application to the Frankfurt and Vienna Stock Exchanges”, European Journal of Operational Research, 181, pp. 1476-1487, 2007.

[7] Ballotta, L., and Fusai, G., "A Gentle Introduction to Value at Risk”, 2017, http://dx.doi.org/10.2139/ssrn.2942138

[8] Benninga, S., Financial Modeling, Massachusetts Institute of Technology Press, $3^{\text {rd }}$ edition, 2008.

[9] Blanchet-Scalliet, C., El Karoui, N., Martellini, L., "Dynamic asset pricing theory with uncertain time-horizon", Journal of Economic Dynamics and Control, 29, pp. 17371764, 2005.

[10] Bravo, M., Pla-Santamaria, D., and Garcia-Bernabeu, A., "Portfolio Selection from Multiple Benchmarks: A Goal Programming Approach to an Actual Case", Journal of Multi - Criteria Decision Analysis, 17, pp. 155 -166, 2010.

[11] Çanakoglu, E., and Özekici, S., "Portfolio selection with imperfect information: A hidden Markov model”, Applied Stochastic Models in Business and Industry, 27, pp. 95-114, 2011.

[12] Castellacci, G., and Siclari, M., "The practice of DeltaGamma VaR: Implementing the quadratic portfolio model”, European Journal of Operational Research, 150, pp. 529545, 2003.

[13] Christoffersen P., Elements of Financial Risk Management, 
Academic Press, $2^{\text {nd }}$ edition, 2011.

[14] Costa, O.L., Paiva, A.C., "Robust portfolio selection using linear-matrix inequality”, Journal of Economic Dynamics and Control, 26, 889-909, 2002.

[15] Dowd, K., An Introduction to Market Risk Measurement, Wileym Finance, 2002.

[16] Fabozzi, F.J., Gupta, F., Markowitz, H.M., “The legacy of modern portfolio theory”, Journal of Investing, 11, pp. 7-22, 2002.

[17] Goldfarb, D., Iyengar, G., "Robust portfolio selection problems”, Mathematics of Operations Research, 28, 1-38, 2003.

[18] Huang, D., Fabozzi, F., and Fukushima, M., "Robust portfolio selection with uncertain exit time using worst-case VaR strategy”, Operations Research Letters, 35, 627 - 635, 2007.

[19] Huang, D., Zhu, Sh., Fabozzi, F., Fukushima, M., "Portfolio selection with uncertain exit time: A robust CVaR approach”, Journal of Economic Dynamics \& Control, 32, pp. 594-623, 2008.

[20] John Wei-Shan $\mathrm{Hu}$, Yi-Chung $\mathrm{Hu}$, Tsan-Ping Yang , "DEMATEL and Analytic Network Process for Evaluating Stock Trade Strategies Using Livermore's Key Price Logic," Universal Journal of Accounting and Finance, Vol. 5, No. 1, pp. 18 - 35, 2017. DOI: 10.13189/ujaf.2017.050103.

[21] Jorion P., "Risk: Measuring the risk in value at risk", Financial Analysts Journal, 52, pp. 47-56, 1996.

[22] Jorion, P., Value at Risk, Mc Graw Hill, Singapore, $3^{\text {rd }}$ edition, 2007.

[23] Karatzas, I., Wang, H., "Utility maximization with discretionary stopping”, SIAM Journal of Control and Optimization, 39, pp. 306-329, 2000.

[24] Lin Cong , "Impact of International Cross-Listing and Delisting on Return Volatility," Universal Journal of
Accounting and Finance, Vol. 5, No. 3, pp. 60 - 71, 2017. DOI: 10.13189/ujaf.2017.050302.

[25] Linsmeier, T., and Pearson, N., Risk Measurement: An Introduction to Value at Risk. Mimeo, University of Illinois Press, 1997.

[26] Liu, Sh., "The mean-absolute deviation portfolio selection problem with interval-valued returns", Journal of Computational and Applied Mathematics, 235, pp. 41494157, 2011.

[27] Magoc, T., and Modave, F., "The optimality of non-additive approaches for portfolio selection", Expert Systems with Applications, 38, pp. 12967-12973, 2011.

[28] Magoc, T., Wang, X., and Modave, R., “Application of Fuzzy Measures and Interval Computation to Financial Portfolio Selection”, International Journal of Intelligent Systems, 25, pp. 621-635, 2010.

[29] Markowitz, H.M., “Portfolio selection”, Journal of Finance, 7, 77-91, 1952.

[30] Markowitz, H.M., Portfolio Selection: Efficient Diversification of Investment, Wiley, New York, 1959.

[31] Martellini, L., Urosevic, B., "Static mean-variance analysis with uncertain time horizon”, Management Science, 52, pp. 955-964, 2006.

[32] Peng, H., Kitagawa, G., Gan, M., and Chen, X., “A new optimal portfolio selection strategy based on a quadratic form mean-variance model with transaction costs”, Optimal Control Applications and Methods, 32, pp. 127-138, 2011.

[33] Rockafellar, R.T., Uryasev, S., "Conditional value-at-risk for general loss distribution”, Journal of Banking and Finance, 26, 1443-1471, 2002.

[34] Zhu, S.S., Fukushima, M., Worst-case conditional value-at-risk with application to robust portfolio management. Technical Report 2005, Kyoto University, 2005 